|Araştırma Makalesi / Research Article |

\title{
Öğrenme Analitiklerine Dayalı Oyunlaştırılmış Gösterge Paneli Kullanımının Öğrencilerin Çevrimiçi Öğrenme Ortamındaki Bağlııklarına Etkisi
}

\section{The Effect of Gamified Learning Analytics Dashboard on Students' Engagement in an Online Learning Environment}

\section{Gökhan Akçapınar ${ }^{1}$, Çiğdem Uz Bilgin ${ }^{2}$}

\author{
Anahtar Kelimeler \\ öğrenme analitikleri \\ oyunlaştırma \\ gösterge paneli \\ bağlılık \\ çevrimiçi öğrenme
}

Keywords
learning analytics
gamification
dashboard
engagement
online learning

Başvuru Tarihi/Received 02.02.2020

Kabul Tarihi /Accepted 09.07.2020
Öz

Bağııık, öğretmenin fiziksel olarak bulunmadığı çevrimiçi öğrenme ortamlarında öğrencilerin derse devam etmesini ve başarılı olmalarını sağlayan önemli değişkenlerden bir tanesidir. Bağlılığın düşük olması, yüksek bırakma oranlarını ve olas başarısızlıkları da beraberinde getirmektedir. Bu nedenle; çevrimiçi öğrenme ortamlarında öğrenci bağlılığını artıracak müdahalelerin tasarlanması önemlidir. Öğrencilerin çevrimiçi öğrenme ortamlarındaki bağlılıklarını artırmanın yollarından bir tanesi öğrenme analitiklerine dayalı gösterge panellerinin kullanılmasıdır. Ancak; yapılan çalışmalar öğrencilerin bu panelleri kullanım durumlarının sınırlı olduğunu ve dolayısıyla öğrenme analitiklerine dayalı gösterge panellerinin tek başına öğrencilerin çevrimiçi öğrenme ortamındaki bağlılıklarını artırmada yetersiz kaldığını göstermektedir. Buradan yola çıkarak planlanan bu çalışmada, öğrenme analitiklerine dayalı olarak tasarlanan gösterge paneline oyunlaştırma öğeleri eklenmiş ve bu şekilde öğrencilerin çevrimiçi öğrenme ortamındaki bağlııklarına bir etkisinin olup olmadığı araştırılmıştır. Araştırmaya uzaktan eğitim yoluyla yürütülen Görsel Programlama dersine kayıtlı 31 öğrenci katılmıştır. Tek gruplu yarı deneysel olarak yapılandırılan çalışmada öğrencilerin oyunlaştırılmış gösterge paneli kullanmadan önceki ve sonraki ders etkileşimleri incelenmiştir. Araştırma sonuçları gösterge paneline oyunlaştırma öğeleri eklenmesinin öğrenci bağııı̆ı̆ını istatistiksel olarak anlamlı derecede artırdığını göstermiştir. Çalışmanın sonuçları çevrimiçi öğrenme ortamlarında bağlılık, gösterge panelleri ve oyunlaştırma bağlamında tartışılmıştır.

\section{Abstract}

Engagement is one of the crucial variables that help students to pursue and be successful in online learning environments where the teacher is not physically present. Low engagement causes high dropout rates and possible academic failures. Therefore, it is important to design interventions that will increase student engagement in online learning environments. One of the ways to increase students' engagement in online learning environments is to use learning analytics dashboards (LADs). However; previous studies show that students' usage of these dashboards are low and therefore, LADs alone can be insufficient to increase students' engagement in an online learning environment. In this respect, this study explores the impact of dashboards with gamification elements that designed based on learning analytics on students' engagement in an online learning environment. Participants were 31 students enrolled in an elective Visual Programming course which is held remotely. In this single-group quasi-experimental study, course interactions of students before and after using the gamified dashboard were explored. Research results showed that adding gamification elements to the dashboard significantly increased student engagement. The results of the study were discussed in the context of engagement, learning analytics dashboards, and gamification in online learning environments.

${ }^{1}$ Sorumlu Yazar, Hacettepe Üniversitesi, Eğitim Fakültesi, BÖTE Bölümü, Ankara, TÜRKiYE; https://orcid.org/0000-0002-0742-1612 ${ }^{2}$ Yıldız Teknik Üniversitesi, Eğitim Fakültesi, BÖTE Bölümü, İstanbul, TÜRKiYE; https://orcid.org/0000-0001-6997-344X

Alıntı/Citation: Akçapınar, G. \& Uz Bilgin, C. (2020). Öğrenme analitiklerine dayalı oyunlaştırılmış gösterge paneli kullanımının öğrencilerin çevrimiçi öğrenme ortamındaki bağlılıklarına etkisi. Kastamonu Education Journal, 28(4), 1892-1901. doi: 10.24106/kefdergi.740489 


\section{Extended Abstract}

\section{Introduction}

Due to the popularity of learning analytics, dashboards have been frequently used in online learning environments to support learning and teaching processes (Verbert et al., 2019). These indicators that depict the students' current or past status graphically are used by instructors to have a general understanding of learning and teaching processes and to apply this knowledge on teaching activities, identifying students' problems, and making data-driven decisions (Verbert et al., 2019). Bodily et al. (2018) developed a dashboard for students in an online learning environment, but only $79 \%$ of the students continued to use the dashboards, although $79 \%$ of them showed a positive attitude towards the dashboards. Dashboards can be successful when they meet the needs of the students and the information they provide is easily comprehensible (Park \& Jo, 2015). Many approaches and theories have also been used to support students to make them utilize dashboards frequently. For example, Aljohani et al. (2019) benefited from the "self-regulated learning" theory and proposed a system consisting of components including instant feedback to increase the motivation of students, recommendations to complete the course successfully, tasks to be completed for each goal, and presentation of students' situations and the problems that they may encounter in the future.

Gamification has recently emerged in the literature as an approach that can be used with learning analytics (Klock et al., 2018). Gamification is the use of game elements and game design in non-game environments in order to motivate individuals (Deterding et al., 2011). Recent studies explored the effect of gamification approach frequently in educational environments and found its positive impact on cooperative learning (Uz Bilgin \& Gül, 2020), academic performance (Kokoç \& Altun, 2019), creative thinking (Aljraiwi, 2019), interaction between students in online learning environments (Huang et al., 2019), students' interest and engagement (Bajko et al., 2016). Gamification is an approach which has principles that overlap with principles of many existing theories and can be used in online environments to increase both intrinsic and extrinsic motivation (Buckle \& Doyle, 2014).

The main purpose of the present study is to examine the effect of gamified learning analytics dashboard on students' engagement and usage behavior in an online learning environment.

\section{Method}

This study conducted at a state university in Turkey at the Department of Computer Education and Instructional Technology. Participants were 31 students enrolled in an elective Visual Programming course offered for second grade students. The course was carried out remotely. Live sessions were held once a week with students, and also students were required to complete weekly tasks in Moodle learning management system. These tasks were regularly logging in to Moodle, studying course resources (e.g. video, pdf files etc.), completing weekly assignments, participating in the discussion forum, and completing weekly quiz activities. The research designed as a four weeks long single group quasi-experimental study. At the beginning of the study, students were informed that any activities they performed in the Moodle environment will be used in the end-of-term evaluation. At the same time, the non-gamified dashboard was introduced to the students and they were informed that they could monitor their activity data on the dashboard. During the first two weeks, regular course activities were carried out without any other intervention. The dashboard could be integrated into the Moodle system, and students were able to access to the dashboard using the link in the course page. At the end of the second week, game elements were added to the dashboard and these game elements were introduced to the students. Moreover, instructor explained how the scores in the dashboard were calculated and the ways to increase these scores. This intervention continued for two weeks. Upon completion of the four-week experimentation period, data of students' Moodle interactions were analyzed.

The dashboard which can be integrated into the Moodle learning management system includes three gamification elements: earning points, making comparison with class mates, and the leaderboard. The interactions and activities of students in the Moodle environment were first converted to 0 to 100 points. These scores were calculated in five different categories: Assignment, Discussion, Quiz, Session and Activity. At the same time, students were able to compare their scores of these five categories with the average score of five students with the highest score. Finally, based on these scores, the names and scores of top three students were presented on the leaderboard. All gamification elements were selected based on the literature and related theories. Data of gamified dashboard was updated once in a day and calculated by taking into account the interactions of students in the last seven days.

In order to analyze the engagement level of students before and after using the gamified dashboard, six categories were identified: total activity, visiting days, assignment, discussion forum, resources, and dashboard. Data was analyzed based on each category which was extracted from the database of Moodle learning management system. Paired groups Wilcoxon test was used to test the effect of gamification on students' engagement.

\section{Result and Discussion}

Descriptive statistics of Moodle interactions and activities of students in both gamified and non-gamified condition were presented in Figure 2. The figure presents boxplots that provide information about the distribution of the data. These boxplots provide information about outliers, minimum value, maximum value, median value, and percentiles (25th, 50th and 75th). The graphs showed that there is an increase in all of the categories in the gamified condition. In other words, students performed 
more activities in the Moodle environment, their visiting times on different days increased, they completed more assignments, they participated more in the discussion forum, they used more resources, and they visited the dashboard more frequently in the gamified condition. According to Wilcoxon test, there was a significant difference between gamified and non-gamified condition in terms of each category (see Table 2). Effect sizes were all large in each category $(r>0.5)$.

As a result; dashboards are important to show a reflection of students' interactions in the online learning environment. In this way, students can monitor and plan their learning processes and make efforts to improve their shortcomings. Adding gamification elements to the dashboards can be used to increase students' motivation to use these panels. 
GíRiş

Son yıllarda çevrimiçi öğrenme ortamlarının artmasıyla birlikte bu ortamlardan elde edilen verilerdeki örüntülerin tespit edilmesine ve analizine yönelik birçok çalışma yapılmış ve öğrenme analitiği kavramı ortaya çıkmıştır (Park ve Jo, 2019, Park ve Jo, 2015). Öğrenme analitiği daha çok öğrenenlerin başarısını artırmak amacıyla geleceğe yönelik tahminlerde bulunmayı ve problemlerin önceden tespit edilmesini amaçlamaktadır (Zilvinskis ve Willis, 2019). Öğrenme analitiğinin popüler olmasıyla birlikte çevrimiçi öğrenme ortamlarında gösterge panelleri öğrenme ve öğretme süreçlerini desteklemek amacıyla sıkça kullanılmaya başlanmıştır (Verbert vd., 2019). Öğrencilerin anlık veya geçmişteki durumlarını grafiksel olarak gösteren bu göstergeler öğretmenlerin öğretim süreci ile ilgili genel bir kanısı olması ve bunu öğretim etkinliklerine yansıtması, öğrencilerin problemlerini tespit etmesi ve veriye dayalı karar vermesi amacıyla kullanılmaktadır (Verbert vd., 2019). Öğrencilerin çevrimiçi davranış örüntülerinin görselleştirilmesini sağlayan göstergeler, öğrencilerin çevrimiçi öğrenme ortamındaki etkileşim verilerini izleyerek ve bu veriler üzerinde veri madenciliği analizleri yaparak anlaşılır sonuçları kullanıcılara sunmaktadır (Park ve Jo, 2015). Göstergeler eğitim sisteminin birer parçası olan öğretmenlere, öğrencilere, velilere veya yöneticilere yönelik olabilmektedir. Park ve Jo'nun (2015) yapmış olduğu derleme çalışmasında göstergelerin en çok öğrencilerin çevrimiçi ortama giriş zamanları ve kullanım eğilimleri, performansları, ortamdaki içerikleri kullanımları, gönderdikleri mesajlar ve yorumların analizi ve sosyal ağ analizlerini sunmak amacıyla kullanıldığını ortaya konmuştur. Ayrıca, 2016 senesinde yapılan derleme çalışmasında göstergelerle yapılan çalışmaların daha çok kullanışlılık ve öğrenci memnuniyetini değerlendirdiğini (\%74), öğrencilerin akademik başarılarına etkisi üzerine yapılan çalışma sayısının oldukça az olduğunu göstermiştir (Schwendimann vd., 2016). Göstergelerin akademik başarı üzerindeki etkisinde olumlu sonuçlar alındığı gibi (Ifenthaler ve Yau, 2020; Kim, Jo ve Park, 2015; Saul ve Wuttke, 2014), bazı çalışmalarda da hiçbir etkisi olmadığı ortaya konmuştur (Ott vd., 2015; Santos vd., 2014; Dodge, Whitmer ve Frazee, 2015). Göstergelerle ilgili yapılan çalışmalar incelendiğinde Bodily vd. (2018) çevrimiçi öğrenme ortamında öğrencilere yönelik gösterge geliştirmiş, ancak öğrencilerin $\% 79^{\prime} u$ göstergelere karşı olumlu tutum göstermelerine rağmen sadece \%25'i göstergeleri kullanmaya devam etmiştir. Göstergeler öğrencilerin ihtiyaçlarını karşıladığında ve bu göstergelerdeki bilgilerin kolay anlaşılabilir olduğu durumlarda amacına ulaşabilmektedir (Park ve Jo, 2015). Öğrencilerin göstergeleri daha çok kullanabilmesi ve yararlanabilmesi amacıyla birçok yaklaşımdan ve kuramdan da faydalanılmıştır. Örneğin Aljohani vd. (2019) “öz düzenleyici öğrenme" kuramından yararlanmış ve öğrencilerin kullanımlarındaki motivasyonlarını arttırmak amacıyla anında geribildirim, dersi başarıyla tamamlamak için öneriler, her bir hedef için tamamlanması gerekenler ve öğrencilerin durumlarını ve ilerleyen zamanlarda karşılaşabilecekleri problemler gibi bileşenlerden oluşan bir sistemin tasarlanmasını önermişlerdir.

Oyunlaştırma da öğrenme analitiğinde kullanılabilecek bir yaklaşım olarak son zamanlarda alanyazında karşımıza çıkmaktadır (de Freitas vd., 2017; Klock vd., 2018). Oyunlaştırma, oyun elementlerinin ve oyun tasarımının oyun olmayan ortamlarda bireyleri motive etmek amaçlı belli bir hedef doğrultusunda kullanılmasıdır (Deterding vd., 2011). Oyunlaştırma eğitim ortamlarında sıkça kullanılmaya başlanmış ve birçok olumlu sonuç elde edilmiştir. Örneğin, işbirlikli öğrenmeye (Uz Bilgin ve Gül, 2020), akademik başarıya (Kokoç ve Altun, 2019), yaratıcı düşünmeye (Aljraiwi, 2019), çevrimiçi öğrenme ortamlarında öğrenciler arası etkileşime (Huang vd., 2019), öğrencilerin derse ilgisine ve bağlılığına (Bajko vd., 2016) olumlu etkileri ortaya konmuştur. Oyunlaştırma hem içsel hem de dışsal motivasyonu arttırarak, birçok kuramla da örtüşen ilkeler bütünüyle (sosyal etkileşimi arttırmak, öğrencilere verilen görevleri kolaydan zora şeklinde sıralamak ve her öğrenciye derste başarılı olma şansı vermek vb.) çevrimiçi ortamlarda da kullanılabilecek bir yaklaşımdır (Buckley ve Doyle, 2014). Nitekim, de Freitas vd.'nin (2017) yaptıkları geniş çaplı araştırmada oyunlaştırılmış gösterge kullanımının çevrimiçi öğrenme ortamında öğrencilerin motivasyon, bağlılık, memnuniyet ve akademik performanslarında olumlu etkisi olduğunu ortaya koymuşlardır.

Bu çalışmada, öğrencilerin çevrimiçi öğrenme ortamındaki etkileşimlerini ve kendileri için hazırlanan gösterge panellerini kullanım durumlarını artırmak amacıyla oyunlaştırmadan yararlanılmıştır. Araştırma kapsamında öğrenme analitiklerine dayalı oyunlaştırılmış gösterge paneli kullanımının öğrencilerin çevrimiçi öğrenme ortamındaki bağlılıklarına ve kullanım davranışlarına etkisini incelemek amaçlanmıştır.

\section{ILGILI ARAŞTIRMALAR}

\section{Oyunlaştırma}

Genel olarak oyun dışı ortamlarda oyun bileşenlerinin kullanılması olarak tanımlanan oyunlaştırma, Kapp (2012) tarafından eğitim ortamları için özelleştirilerek oyun mekaniklerinin, estetik ve oyunsal düşünmenin bireylerin bağlılı̆ını, motivasyonunu, öğrenmelerini ve problem çözme becerilerini desteklemeye yönelik kullanılması şeklinde tanımlanmıştır. Hunicke, LeBlanc ve Zubek (2004) de benzer unsurlardan bahsetmektedir ve geliştirdikleri oyunlaştırma modeli mekanikler, estetik ve dinamikler olmak üzere üç temel unsurdan oluşmaktadır. Hunicke vd.'e (2004) göre, mekanikler veri gösterimi ve algoritma seviyesindeki bileşenlerden (puan, rozet, görevler, seviyeler, ödüller ve kurallar) oluşmaktadır. Dinamikler ise bireylere estetik deneyimi kazandırmak için uygulanan oyun kurallarıdır, örneğin kişiler arası meydan okuma ve rekabeti desteklemek için zaman sınırlaması gibi kuralların kullanılması bu kategoride değerlendirilebilir. Estetik bileşeni de kişilerin tüm bu bileşenler karşısında verdikleri duygusal tepkilerdir; heyecan, memnuniyet, meydan okuma vb. duygu durumları bu kategoriye girmektedir. Bunun yanında Simoes vd. (2013) K-6 seviyesindeki öğrenenlere yönelik sosyal oyunlaştırma modelini önermiş ve bu modelde mekaniklerden (puan, rozet, sanal hediyeler vb.) ve dinamiklerden (statü, başarı, yarışma, meydan okuma) bahsetmiştir. Bunchball (2010) ise bireylerin oyun mekaniklerinden motive olmasını oyun dinamiklerine bağlamaktadır. Bireylerin temel ihtiyaç ve istekleri olan oyun 
dinamikleri başarılı olma, ödüllendirilme, kendini ifade edebilme, rekabet ve başkaları tarafından tanınma/kabul görme gibi arzulardır ve oyun tasarımcıları tarafından yıllarca bilinmekte ve kullanılmaktadır ve oyunlaştırma ile farklı alanlarda da kullanılmaya başlanmıştır (Bunchball, 2010). Kapp'e (2012) göre puan, rozet veya lider tahtaları oyunlaştırmanın en önemsiz unsurları iken, problem çözme, bağlıık ve oyun temelli düşünme gibi unsurlar oyunlaştırmanın asıl odak noktası olmalıdır. Oyunlaştırma, temelinde birçok kuramı barındıran (Akış Kuramı, Sosyal Öğrenme Kuramı, ARCS Motivasyon Kuramı vd.), yeni olmayan ve uygulaması zor bir yaklaşımdır, oyun bileşenleri öğrenme ortamı ve oyun hedefleri göz önünde bulundurularak seçilmeli ve uygulanmalıdır (Kapp, 2012).

Simoes vd.'nin (2013) öğrenme ortamlarının oyunlaştırılmasına yönelik geliştirdiği öneriler şu şekildedir: hızlı geribildirimler verilmesi, görevlerin öğrencilerin becerilerine göre gittikçe zorlaştırılması, zor görevlerin alt görevlere bölünmesi, öğrenenlerin başarılarının arkadaşları, öğretmenleri ya da aileleri tarafından görülmesi ve onaylanması ve ödüllendirmenin arttırılması şeklindedir. Zichermann ve Cunningham (2011) ise öğrencilerin sadece akademik başarı değil farklı alanlarda da rozet, puan alabilmeleri ya da ödüllendirilmeleri gerekliliği üzerinde durmuş ve herkese başarılı olma şansı verilmesi gerektiğini vurgulamıştır.

Çevrimiçi öğrenme ortamlarında da oyunlaştırma kullanılmış ve bu yaklaşımın öğrenci bağlılı̆ına (da Rocha Seixas vd., 2016), akran geribildirimine (Huang vd., 2019), yaratıcı düşünme ve akademik başarıya (Aljraiwi, 2019) olumlu etkileri olduğu bulunmuştur. Muntean'nın (2011) e-öğrenmenin oyunlaştırılmasına yönelik önerileri şu şekildedir: öğrencilerin e-öğrenme ortamında profillerini kendi tercihlerine göre düzenleyebilmesi, öğrencilerin dersin en başından beri tüm görevlerden, hedeflerden ve gelecekte kendilerini nelerin beklediğinden haberdar olması, içeriklerin bölümlere ayrılması ve bölüm sonlarında öğrencilerin değerlendirilmesi ve ödüllendirilmesi, öğrencilerin durumlarını skor tablolarından takip edebilmeleri, öğrencilerin geribildirim alabilmesi ve ilerleme durumlarını sistemden göstergeler aracılığıyla takip edebilmeleri, e-öğrenme ortamının sosyal olması ve öğrenenlerin arkadaşları tarafından onay alma veya kendilerini sınıf arkadaşları ile karşılaştırabilme olanaklarına sahip olması ve öğrenenlerin sadece akademik başarılarıyla değil çevrimiçi ortamda arkadaşlarına yardım etme/platformda yorum yazma veya platformu aktif kullanma gibi etkinliklerinin de puanlandırıması veya rozet vb. ödüllerin verilmesi şeklindedir.

Çevrimiçi öğrenme ortamındaki oyunlaştırma yaklaşımına yönelik önerilere bakıldığında öğrencilerin kendi durumlarını takip edebilmeleri ve sınıf arkadaşlarına göre durumlarını görebilmeleri, çevrimiçi öğrenme ortamını kullanım durumlarının tespit edilmesi ve ilerleme durumlarının gösterimi gibi öneriler öğrenme analitiğinin oyunlaştırma ile birlikte kullanılmasının gerekliliğini ortaya koymaktadır.

\section{Oyunlaştırma ve Bağlılık}

Alanyazında e-öğrenme ortamlarında oyunlaştırma yaklaşımı kullanılarak öğrencilerin ortama bağlılıklarına yönelik bazı araştırmalar ortaya konmuştur. De-Marcos vd. (2014) sosyal medya ve oyunlaştırılmış e-öğrenme ortamlarının öğrencilerin katılımına, tutumuna ve performansına etkisine bakmıştır. Her bir aktivite farklı seviyelere bölünmüş ve öğrencilerin tamamlama durumlarına göre ödül, rozetler ve lider tahtalarında öğrencilerin puanlarının karşılaştırılması yapılmıştır. Öğrencilerin oyunlaştırılmış e-öğrenme ortamında akademik performansı ve tutumları artış gösterirken, sosyal medya ortamında ve geleneksel e-öğrenme ortamında daha fazla katılım göstermişlerdir. Krause vd. (2015) e-öğrenme ortamını rozet, puan tablosu, kendi avatarlarını tasarlayabilmeleri ve durumlarını gösterge panelinde izleyebilmeleri gibi oyunlaştırma öğeleri eklemiş, ayrıca başka bir öğrenci grubuna da sosyal oyunlaştırma öğelerini ekleyerek grupları karşılaştırmıştır. Oyunlaştırma ve özellikle sosyal öğelerin eklendiği oyunlaştırma yaklaşımının kullanımı öğrencilerin e-öğrenme ortamında daha fazla zaman harcadıkları ve daha fazla video izledikleri ortaya konmuştur. Kyewski ve Krämer (2018) yaptıkları çalışmada sadece oyunlaştırmada rozet kullanımının etkisini incelemiş ve öğrencilerin aktivitelerine ve motivasyonlarına önemli bir katkısı olmadığını bulmuşlardır ve ayrıca öğrencilerin sadece kendi rozetlerini görebildiği durumda daha olumlu görüş bildirdiklerini belirtmişlerdir. Sitra vd. (2017) rozet kullanımını özel eğitim öğrencilerindeki etkileri üzerine bir çalışma gerçekleştirmiş ve yaptıkları az katılımcılı durum çalışmasında rozet kullanımının öğrencilerin bağlılıklarına olumlu etkisi olduğunu bulmuşlardır ve özellikle dikkat bozukluğu olan bu öğrencilerde rozetlerin dikkatlerini çekmede önemli etkisi olduğunu belirtmişlerdir.

Upadhyaya ve Garg (2019) yaptıkları çalışmada e-öğrenme ortamında oyunlaştırmayı öğrenme analitiği ile destekleyen ve öğrencilerin çevrimiçi ortama girmelerini, kullanım sürelerini ve aktiviteleri bitirme durumlarını öğrenme analitiği kullanarak öğrencilere puanlar, rozetler verilmesi ve lider tablolarının kullanılması gibi oyun bileşenlerini dahil ederek öğrencilerin katılımlarının arttırımasına yönelik bir çerçeve çizmişlerdir. Cassano vd. (2018) yaptıkları çalışmada e-öğrenme ortamı mobil uygulamayla desteklenmiş ve oyunlaştırma öğeleri kullanılmıştır. Öğrenciler viki sayfasını okumaları, yazılanları beğenmeleri veya yorum yazmaları, viki sayfası oluşturmaları gibi aktiviteleri gerçekleştirme durumlarına göre puanlar almış ve rozetlerle ödüllendirilmiştir, öğrenme analitiği kullanılarak öğrencilerin durumları izlenmiş ve geliştirilen uygulama kullanışlılık ve kabul edilme açısından olumlu sonuçlar elde edilmiştir.

Alanyazında öğrenme analitiği ve oyunlaştırma bileşenlerinin bir arada kullanıldığı gösterge panellerinin öğrencilerin bağlılıklarına etkisinin incelendiği deneysel araştırmalar konusunda eksiklik olduğu saptanmış ve bu çalışma ile ilerideki çalışmalara da ışık tutulması amaçlanmıştır. 


\section{YÖNTEM}

\section{Katılımcılar ve Veri Toplama Süreci}

Çalışma, Türkiye'de bir devlet üniversitesine Bilgisayar ve Öğretim Teknolojileri Eğitimi Bölümünde Görsel Programlama dersinde yürütülmüştür. íkinci sınıf öğrencileri için seçmeli olarak sunulan derse 31 öğrenci kayıt yaptırmıştır. Ders tamamen uzaktan eğitim ile yürütülmüştür. Öğrencilerle haftada bir gün canlı ders yapılmışıı, canlı ders dışında da öğrencilere Moodle öğrenme yönetim sistemi üzerinden haftalık olarak görevler verilmiştir. Bu görevler; Moodle'a düzenli olarak giriş yapmak, video, pdf vb. ders kaynaklarına çalışmak, haftalık ödevleri yapmak, tartışma ortamına katılmak ve haftalık değerlendirme etkinliklerini tamamlamak şeklindedir. Araştırma, tek grup yarı-deneysel olarak planlanmış ve dört hafta sürmüştür. Çalışmanın başında öğrencilere Moodle ortamında yaptıkları her türlü aktivitenin dönem sonu değerlendirmesinde kullanılacağı bildirilmiştir. Aynı zamanda oyunlaştırma olmayan gösterge paneli öğrencilere tanıtılmıs ve yaptıkları aktivitelere ilişkin verileri gösterge paneli üzerinden izleyebilecekleri bildirilmiştir. İlk iki hafta süresince öğrencilere başka bir müdahale yapılmamış normal ders etkinlikleri devam etmiştir. Gösterge paneli Moodle sistemine entegre şekilde tasarlanmıştır ve öğrenciler ders sayfasındaki bağlantıyı kullanarak gösterge paneline erişmişlerdir. Ikinci haftanın sonunda gösterge paneline oyunlaştırma öğeleri eklenmiş ve öğrencilere yeni bir bilgilendirme yapılmıştır. Bu bilgilendirmede öğrencilere yeni eklenen oyunlaştırma öğeleri tanıtılmış, burada yer alan puanların nasıl hesaplandığı ve puanlarını artırmak için neler yapabilecekleri açıklanmıştır. Öğrencilere başka bir müdahale yapılmadan iki hafta süreyle derslere devam edilmiştir. Dört haftalık süre tamamlandığında öğrencilerin Moodle etkileşimlerine ilişkin veriler analiz edilmiştir.

\section{Öğrenme Analitiklerine Dayalı Gösterge Paneli}

Çalışma kapsamında kullanılan gösterge panelinin bileşenleri Şekil 1'de sunulmuştur. Moodle öğrenme yönetim sistemine entegre olarak çalışan bu panelde öğrenciler için dört bilgi yer almaktadır. (A) Günlük etkileşim: Bu alanda öğrencinin son 7 gün içerisinde Moodle'da gerçekleştirdiği etkileşim sayısı günlük olarak gösterilmektedir. Bu sayede öğrenci gün gün öğrenme ortamında ne kadar aktif olduğunu görebilmektedir. (B) Tartışma ortamı: Burada ise öğrenciye son 7 gün içerisinde dersin tartışma ortamında yaptığı aktivitelere ilişkin bilgiler verilmektedir. Bu bilgiler; tartışma ortamındaki soruları görüntüleme sayısı, soru sorma sayısı, cevap yazma sayısı ve silme sayısı şeklindedir. Bu sayede öğrenci tartışma ortamında ne kadar aktif olduğunu izleyebilmektedir. (C) Haftalık özet: Öğrencilerin son 7 gün içerisinde sistemde gerçekleştirdikleri etkileşimlerden 0-100 arası standartlaştııılmış puanlar üretilmektedir ve bu puanlar radar grafiği şeklinde öğrencilerle paylaşılmaktadır. Burada öğrenciler gerçekleştirdikleri etkileşimleri Ödev, Tartışma, Quiz, Oturum ve Aktivite başlıklarında görebilmektedirler. Bu ekranda öğrenci kendi puanlarına ek olarak sınıfta en yüksek puan alan 5 öğrencinin ortalama puanlarını da görebilmektedir. Bu sayede kendisini sınıftaki başarılı öğrenciler ile karşılaştırabilmektir. (D) Lider tahtası: Burada ise ortalama puana göre en yüksek puan alan ilk üç öğrencinin isimleri ve puanları paylaşılmaktadır.

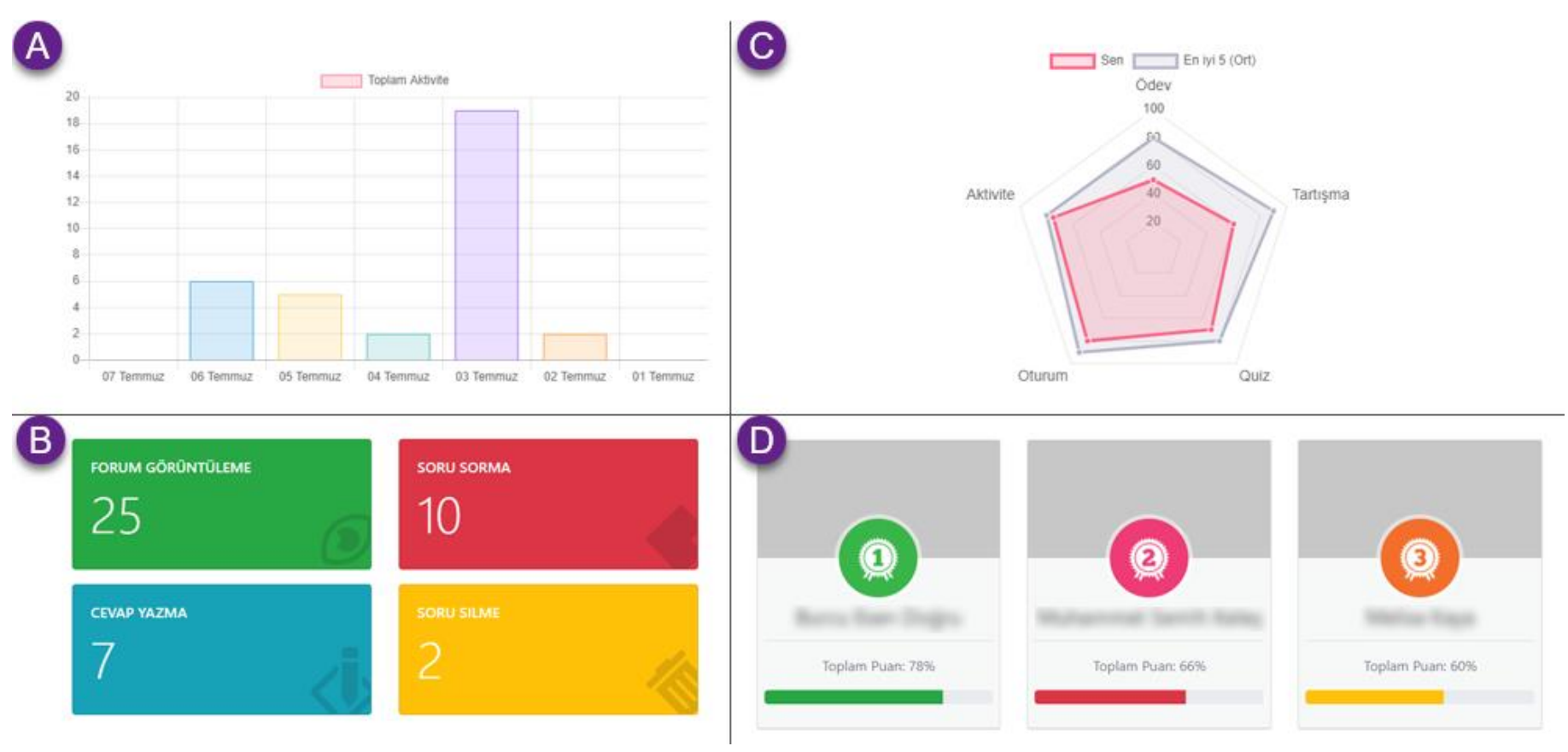

Şekil 1. Oyunlaştırılmış Öğrenme Analitiği Gösterge Panelinin Bileşenleri 


\section{Gösterge Panelinde Yer Alan Oyunlaştırma Öğeleri}

Geliştirilen gösterge panelinde üç adet oyunlaştırma öğesine yer verilmiştir. Bunlar; puan toplama, sınıf ile karşılaştırma ve lider tahtası şeklindedir. Oyunlaştırma amacıyla ilk olarak öğrencilerin Moodle ortamında gerçekleştirdikleri etkileşimler 0-100 arası puanlara çevrilmiştir. Bu puanlar Ödev, Tartışma, Quiz, Oturum ve Aktivite olmak üzere beş farklı kategoride hesaplanmıştır. Aynı zamanda öğrencilere bu beş kategoriden aldıkları puanları sınıfta en yüksek puan alan beş öğrencinin ortalaması ile karşılaştırma olanağı verilmiş̧tir. Son olarak da beş kategoriden alınan ortalama puana göre ilk üç sıradaki öğrencilerin isimleri ve puanları lider tahtasında paylaşıımışır. Oyunlaştırma öğelerinin neler olacağına ve ne tür veriler içereceğine ilgili alanyazın ışığında karar verilmiştir. Oyunlaştırma ile ilgili verilerin hepsi günde bir defa güncellenmiş ve öğrencilerin son yedi gündeki etkileşimleri dikkate alınarak hesaplanmıştır. Verilerin son yedi gün ile sınırlandıııması sayesinde öğrencilere her gün için lider tahtasında üst sıralara çıkma fırsatı verilmiştir. Bu sayede alanyazında belirtilen ve oyunlaştırmanın düşük performanslı öğrenciler üzerinde neden olabileceği olumsuz etkilerin en aza indirilmesi amaçlanmıştır.

Gösterge panelinde yer verilen bu öğelerin yanında derse ilişkin olarak da oyunlaştırmanın diğer önemli unsurlarından yararlanılmıştır. Bunlar; geribildirimlerin yeterli düzeyde ve zamanında verilmesi, öğrencilerin dersin başında görevlerden, alacakları puanlardan ve ders süresince gerçekleştirmeleri gereken hedeflerden haberdar edilmesi, her öğrencinin başarı gösterebilmesi için farklı kategorideki görevlere yer verilmesi ve böylelikle her öğrenciye başarı şansı verilmesi, öğrencilerin sınıf ile kendilerini karşılaştırmaları ancak düşük puan alanların lider tablolarında ilan edilmemesi, öğrencilerin tartışma vb. sosyal aktivitelere de teşvik edilmesi şeklindedir.

\section{Veri Analizi}

Öğrencilerin oyunlaştırılmış gösterge paneli kullanmadan önceki ve sonraki etkileşimlerini analiz edebilmek için öğrencilerin sistemdeki bağlııklarının göstergesi olan altı adet değişken belirlenmiştir. Değişkenlerin neler olduğu ve açıklamaları Tablo 1'de sunulmuştur. Veri analizi aşamasında her bir öğrencinin her bir değişkene ilişkin verileri sadece gösterge panelinin kullanıldığı iki hafta ve oyunlaştırılmış gösterge panelinin kullanıldığı iki hafta için Moodle veri tabanından elde edilmiştir. Veriler veri tabanından araştırmacılar tarafından geliştirilen bir yazııı ile elde edilmiştir, verilerin analizi $R$ yazııımı kullanılarak gerçekleştirilmiştir. Oyunlaştırma öğelerinin öğrencilerin Moodle kullanımına etkisine bakmak için bağımlı gruplar Wilcoxon testi kullanılmıştır.

Tablo 1. Araştırmada kullanılan değişkenler ve açıklamaları

\begin{tabular}{ll}
\hline Değişken & Açıklama \\
\hline Toplam aktivite & $\begin{array}{l}\text { Öğrencilerin Moodle ortamında gerçekleştirdikleri her türlü etkileşimin (ör: dersi görüntüleme, ödev gönderme, canlı derse katılma vb.) } \\
\text { toplam sayısı }\end{array}$ \\
Ziyaret gün & Uygulama süresince öğrencilerin Moodle'ı ziyaret ettikleri farklı gün sayısı \\
Ödev & Öğrencilerin ödev etkinliklerinde gerçekleştirdiği etkileşim sayısı (ör: ödev görüntüleme, ödev oluşturma, gönderme vb.) \\
Tartışma & Öğrencilerin tartışma etkinliklerinde gerçekleştirdiği etkileşim sayısı (ör: tartışma görüntüleme, soru sorma, cevap yazma vb.) \\
Kaynak & Öğrencilerin ders kaynaklarını görüntüleme sayısı \\
Gösterge paneli & Öğrencilerin gösterge panelini ziyaret etme sayısı \\
\hline
\end{tabular}

\section{BULGULAR}

Öğrencilerin oyunlaştırma olan ve olmayan gösterge paneli kullandıkları durumdaki Moodle etkileşimlerine ilişkin tanımlayıcı istatistikler Şekil 2'de görsel olarak sunulmuştur. Şekilde yer alan kutu grafikler aynı zamanda verideki dağılım hakkında da bilgi vermektedir. Bu sayede verideki aykırı değerler, en küçük değer, en büyük değer, ortanca değer ve yüzdelikler (25., 50. ve 75.) hakkında bilgi elde edilebilmektedir. Grafikler incelendiğinde oyunlaştırma kullanılan durumda seçilen değişkenlerin hepsi açısından bir artı̧̧ olduğu görülmektedir. Öğrenciler oyunlaştırma kullanılan durumda; Moodle ortamında daha fazla aktivite yapmışlardır, Moodle'ı ziyaret ettikleri farklı gün sayısı artmış̧ır, ödev etkinliklerini daha fazla ziyaret etmişlerdir, tartışma ortamına daha çok katılmışlardır, kaynakları daha fazla görüntülemişlerdir ve gösterge panelini daha fazla ziyaret etmişlerdir. 


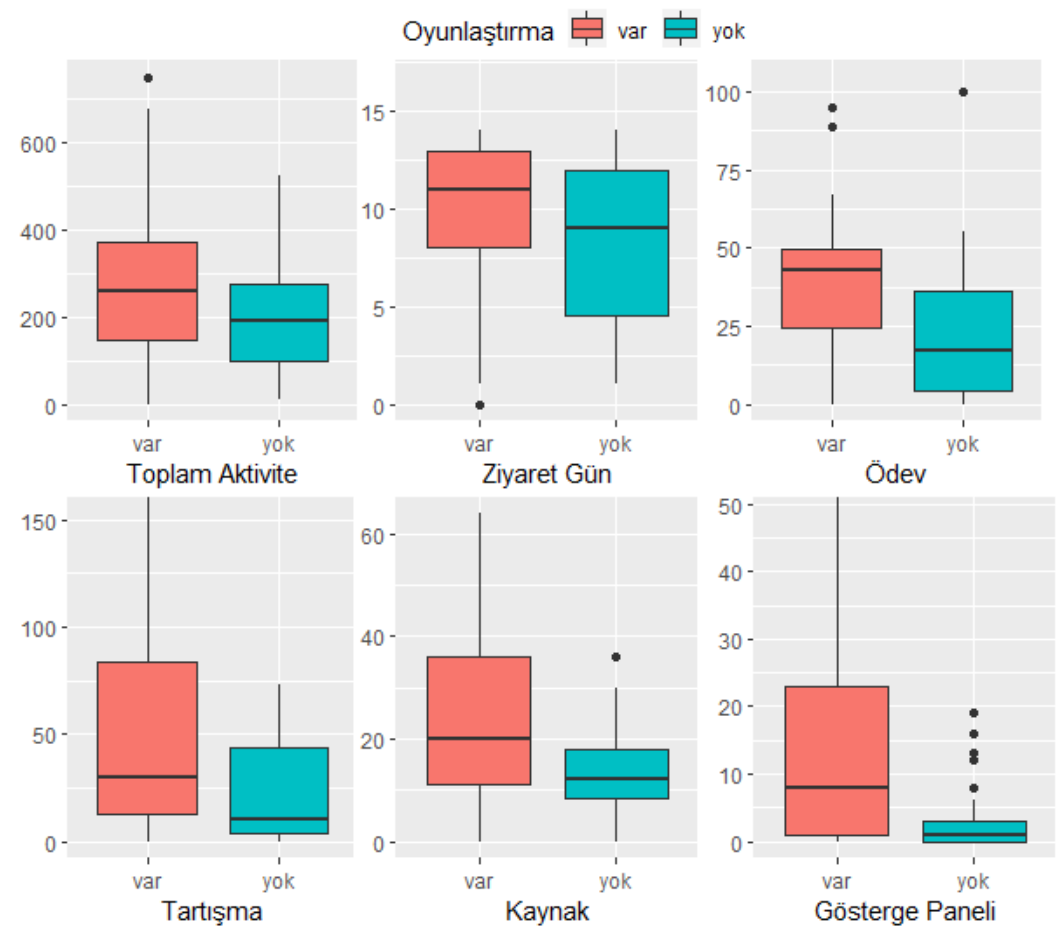

Şekil 2. Araştırmada Kullanılan Değişkenlere iliş̧kin Kutu Grafikleri

\section{Wilcoxon Testi Sonuçları}

Oyunlaştırılmış gösterge panelinin öğrencilerin bağlııklarına etkisini test etmek için gerçekleştirilen bağımlı gruplar Wilcoxon testine ilişkin sonuçlar Tablo 2'de sunulmuştur. Buna göre; oyunlaştırma öğelerinin kullanıldığı ve kullanılmadığı durumda seçilen değişkenlerin tamamında ortanca değerler açısından istatistiksel olarak anlamlı fark bulunmuştur. Diğer bir ifade ile; oyunlaştırma kullanılan durumda öğrenciler Moodle ortamında daha fazla aktivite gerçekleştirmiş, öğrenme ortamını haftanın daha fazla gününde ziyaret etmiş, ödev etkinlikleri ile ilgili daha fazla aktivite gerçekleştirmiş, tartışma ortamına daha aktif katılmış, ders kaynaklarını daha fazla görüntülemiş ve gösterge panelini daha fazla ziyaret etmiştir. Elde edilen bulgular etki büyüklüğü açısından değerlendirildiğinde de seçilen değişkenlerin tamamı için aradaki farkın büyük etki büyüklüğüne sahip olduğu görülmüştür $(r>$ $0,5)$.

Tablo 2. Bağımlı gruplar Wilcoxon testi sonuçları

\begin{tabular}{lccccc}
\hline Değişken & $\begin{array}{c}\text { Oyunlaştırma Yok } \\
\text { (Ortanca) }\end{array}$ & $\begin{array}{c}\text { Oyunlaştırma Var } \\
\text { (Ortanca) }\end{array}$ & $\mathrm{v}$ & $\mathrm{p}$ & $\mathrm{r}$ \\
\hline Toplam aktivite & 189 & 257 & 403 & 0,001 & 0,546 \\
Ziyaret gün & 9 & 11 & 214 & 0,004 & 0,508 \\
Ödev & 17 & 43 & 387 & $<0,001$ & 0,666 \\
Tartışma & 10 & 30 & 391 & $<0,001$ & 0,666 \\
Kaynak & 12 & 20 & 408 & $<0,001$ & 0,643 \\
Gösterge paneli & 1 & 8 & 343 & $<0,001$ & 0,770 \\
\hline
\end{tabular}

\section{SONUÇ VE TARTIŞMA}

Bu çalışmada öğrenme analitiklerine dayalı oyunlaştııılmı̧ gösterge paneli kullanımının uzaktan eğitim ile ders alan öğrencilerin çevrimiçi öğrenme ortamındaki bağlılıkları üzerine etkisine bakılmıştır. Bu amaçla tek gruplu yarı-deneysel bir araştırma planlanmış ve uzaktan eğitim ile ders alan öğrencilerin oyunlaştııılmış gösterge paneli kullanılan ve kullanılmayan durumlardaki Moodle etkileşimlerine ilişkin veriler toplanmıştı. Öğrencilere ilk iki hafta oyunlaştırma öğeleri olmadan gösterge paneli sunulmuş kalan iki hafta da oyunlaştırma öğeleri içeren gösterge paneli sunulmuştur. Elde edilen sonuçlar gösterge paneline oyunlaştırma öğeleri eklendikten sonra öğrencilerin Moodle ortamındaki etkileşimlerinde istatistiksel olarak anlamlı derecede artı̧ olduğunu göstermiştir. Özellikle oyunlaştırma kullanılmadığı durumda öğrencilerin gösterge paneli görüntüleme sayılarının oldukça düşük olduğu görülmektedir. Ödev etkileşimlerinde ve Tartışma ortamına katılımlarında da önemli derece artış olduğu görülmektedir. Alanyazında da gösterge panelinin tek başına kullanıldı̆ı durumlarda öğrencilerin kullanımının sınırlı olduğu gösteren çalışmalar bulunmaktadır. Diğer taraftan elde edilen bulgular çevrimiçi derslerde oyunlaştırma öğelerinin kullanılmasının öğrencilerin motivasyonunu ve bağılıı̆ını olumlu yönde artırdığını gösteren çalışmalar ile de uyumludur (Krause vd., 2015; Sitra vd., 2017). Bununla birlikte gösterge paneline oyunlaştırma öğelerinin eklenmesi sonucu öğrencilerin bağlııklarındaki artışa "yenilik etkisinin" de sebep olabileceği göz önünde bulundurulmalıdır. Katılımcılara yeni bir yöntemin veya aracın uygulanması sonucunda uygulanan 
araçtan veya yöntemden bağımsız olarak katılımcıların performanslarının etkilenebileceği yönünde çalışmalar bulunmaktadır (Glass, 2010).

Alanyazında oyunlaştırmanın öğrencilerin bağlıı̆̆ına çok etkisi olmadığı yönünde de araştırmalar bulunmaktadır (De-Marcos vd., 2014; Kyewski ve Krämer, 2018). Kyewski ve Krämer (2018), öğrencilerin kazandıkları rozetleri sadece kendi görebildikleri durumda daha olumlu görüş bildirmişlerdir. Nitekim bu çalışmada öğrenciler farklı beş kategoriden aldıkları puanları sınıfla karşılaştırabilmekte ve bunu sadece kendileri görebilmektedir. illan edilen lider tahtasında sadece en yüksek puan alanlar gösterilmekte ve düşük puanlılara yer verilmemektedir. De-Marcos vd. (2014) ise sosyalliği destekleyen sosyal ağların bağlılıkta daha çok etkili olduğunu ortaya koymuştur. Bu çalışmada öğrenciler çevrimiçi ortamda tartışmalara katılmaları da teşvik edilmiş, forum ortamın soru sorma, cevap yazma gibi aktiviteleri kayıt altına tutulmuş ve ödüllendirilmiştir. Bu çalışma, oyunlaştırma yaklaşımının etkili bir şekilde kullanıldığında olumlu sonuçlar ortaya koyulabileceğini göstermektedir.

Yapılan çalışmalar öğrencilerin çevrimiçi öğrenme ortamlarında yüksek bırakma oranlarına sahip olduğunu göstermektedir. Özellikle öğrencilerin kendi istekleri ile derslere kayıt oldukları çevrimiçi kitlesel ders platformlarında (MOOC) bu oranlar \%90’lara kadar çıkabilmektedir (Rivard, 2013). Oyunlaştırılmış gösterge panelleri öğrencilerin ders bırakma oranlarının azaltılmasında etkili bir yöntem olabilir. Öğrenme analitiklerine göre hesaplanan puanlar makine öğrenmesi yöntemleri ile analiz edilerek dersi bırakma riski yüksek öğrencilerin belirlenmesinde ve bu öğrencilere yönelik müdahalelerin geliştirilmesi amacıyla kullanılabilir (Akçapınar, Altun ve Aşkar, 2019). Bununla birlikte çevrimiçi kitlesel ders platformlarında öğrencilerin notlandırılması, dersi geçme veya kalma gibi durumlarının olmaması da unutulmamalıdır. Ilerideki çalışmalarda bu tür gösterge panellerinin, notlandırma, geçme veya kalma gibi durumların olmadığı kitlesel çevrimiçi öğrenme ortamlarındaki etkisi de incelenebilir.

Bu çalışmada tek gruplu yarı-deneysel araştırma yöntemi kullanılmıştır. Bu tür araştırmalarda, uygulamaların tek grupla sınırlı kalmasından ötürü kontrol grubu kullanılmaması, aynı öğrencilere farklı uygulamaların uygulanıp karşılaştırmanın tek grupla sınırlı kalması bu araştırmanın sınırlılıklarına dahil edilebilir. İlerideki çalışmalarda bu araştırma, farklı deneysel düzenlerle ve daha fazla kullanıcılı çevrimiçi öğrenme ortamlarında tekrarlanabilir. Ayrıca, yapılan çalışma oyunlaştırılmış gösterge panelinin öğrencilerin çevrimiçi öğrenme ortamındaki bağlılıklarına etkisi ile sınırlı tutulmuştur. İlerleyen çalışmalarda öğrencilerin akademik başarısına ve derse karşı motivasyonlarına etkisi de araştırılabilir.

Sonuç olarak; gösterge panelleri öğrencilerin çevrimiçi öğrenme ortamındaki etkileşimlerinin bir yansımasını göstermesi açısından önemlidir. Öğrenciler bu sayede öğrenme süreçlerini izleyebilir, planlayabilir ve eksik yönlerini geliştirmek için çaba harcayabilirler. Gösterge panellerine oyunlaştırma öğelerinin eklenmesi ise öğrencilerin bu panelleri kullanmaya yönelik motivasyonlarının artırılması amacıyla kullanılabilir.

\section{KAYNAKÇA}

Akçapınar, G., Altun, A., \& Aşkar, P. (2019). Using learning analytics to develop early-warning system for at-risk students. International Journal of Educational Technology in Higher Education, 16(1), 40. doi:10.1186/s41239-019-0172-z

Aljohani, N. R., Daud, A., Abbasi, R. A., Alowibdi, J. S., Basheri, M., \& Aslam, M. A. (2019). An integrated framework for course adapted student learning analytics dashboard. Computers in Human Behavior, 92, 679-690. doi:10.1016/j.chb.2018.03.035

Aljraiwi, S. (2019). Effectiveness of Gamification of Web-Based Learning in Improving Academic Achievement and Creative Thinking among Primary School Students. International Journal of Education and Practice, 7(3), 242-257.

Bajko, R., Hodson, J., Seaborn, K., Livingstone, P., \& Fels, D. (2016). Edugamifying Media Studies: Student Engagement, Enjoyment, and Interest in Two Multimedia and So-cial Media Undergraduate Classrooms. Information Systems Education Journal, 14(6), 55.

Bodily, R., Ikahihifo, T. K., Mackley, B., \& Graham, C. R. (2018). The design, development, and implementation of student-facing learning analytics dashboards. Journal of Computing in Higher Education, 30(3), 572-598.

Buckley, P., \& Doyle, E. (2014). Gamification and student motivation. Interactive Learning Environments, $1162-1175$. doi:10.1080/10494820.2014.964263

Bunchball, I. (2010). Gamification 101: An introduction to the use of game dynamics to influence behavior. White paper, 9.

Cassano, F., Piccinno, A., Roselli, T., \& Rossano, V. (2018, Haziran). Gamification and learning analytics to improve engagement in university courses. In International Conference in Methodologies and intelligent Systems for Techhnology Enhanced Learning (pp. 156-163). Springer, Cham.

de Freitas, S., Gibson, D., Alvarez, V., Irving, L., Star, K., Charleer, S., \& Verbert, K. (2017, April). How to use gamified dashboards and learning analytics for providing immediate student feedback and performance tracking in higher education. In Proceedings of the 26th international conference on world wide web companion (pp. 429-434).

De-Marcos, L., Domínguez, A., Saenz-de-Navarrete, J., \& Pagés, C. (2014). An empirical study comparing gamification and social networking on e-learning. Computers \& Education, 75, 82-91.

da Rocha Seixas, L., Gomes, A. S., \& de Melo Filho, I. J. (2016). Effectiveness of gamification in the engagement of students. Computers in Human Behavior, 58, 48-63.

Deterding, S., Sicart, M., Nacke, L., O Hara, K., \& Dixon, D. (2011). Gamification: Using game-design elements in non- gaming con- texts. In Proceedings. CHI EA '11 Extended Abstracts on Human Factors in Computing Systems (pp. 2425-2428). New York: ACM. 
Dodge, B., Whitmer, J., \& Frazee, J. P. (2015, Mart). Improving undergraduate student achievement in large blended courses through data-driven interventions. In Proceedings of the Fifth International Conference on Learning Analytics and Knowledge (pp. 412-413).

Glass, S. D. (2010). The practical handbook of group counseling. Trafford Publishing.

Huang, B., Hwang, G. J., Hew, K. F., \& Warning, P. (2019). Effects of gamification on students' online interactive patterns and peer-feedback. Distance Education, 40(3), 350-379.

Hunicke, R., LeBlanc, M., \& Zubek, R. (2004, July). MDA: A formal approach to game design and game research. In Proceedings of the AAAl Workshop on Challenges in Game Al (Vol. 4, No. 1, p. 1722).

Ifenthaler, D., \& Yau, J. Y. K. (2020). Utilising learning analytics to support study success in higher education: a systematic review. Educational Technology Research and Development, 1-30.

Kapp, K.M. (2012). The gamification of learning and instruction: Game- based methods and strategies for training and education. San Francisco: Pfeiffer.

Kim, J., Jo, I. H., \& Park, Y. (2016). Effects of learning analytics dashboard: analyzing the relations among dashboard utilization, satisfaction, and learning achievement. Asia Pacific Education Review, 17(1), 13-24.

Klock, A. C. T., Ogawa, A. N., Gasparini, I., \& Pimenta, M. S. (2018, April). Does gamification matter? A systematic mapping about the evaluation of gamification in educational environments. In Proceedings of the 33rd Annual ACM Symposium on Applied Computing (pp. 2006-2012).

Kokoç, M., \& Altun, A. (2019). Effects of learner interaction with learning dashboards on academic performance in an e-learning environment. Behaviour \& Information Technology, 1-15.

Krause, M., Mogalle, M., Pohl, H., \& Williams, J. J. (2015, March). A playful game changer: Fostering student retention in online education with social gamification. In Proceedings of the Second (2015) ACM conference on Learning@ Scale (pp. 95-102).

Kyewski, E., \& Krämer, N. C. (2018). To gamify or not to gamify? An experimental field study of the influence of badges on motivation, activity, and performance in an online learning course. Computers \& Education, 118, 25-37.

Muntean, C. I. (2011, October). Raising engagement in e-learning through gamification. In Proc. 6th international conference on virtual learning ICVL (Vol. 1, pp. 323-329).

Ott, C., Robins, A., Haden, P., \& Shephard, K. (2015). Illustrating performance indicators and course characteristics to support students' selfregulated learning in CS1. Computer Science Education, 25(2), 174-198.

Park, Y., \& Jo, I. H. (2015). Development of the learning analytics dashboard to support students' learning performance. Journal of Universal Computer Science, 21(1), 110

Park, Y., \& Jo, I. H. (2019). Factors that affect the success of learning analytics dashboards. In Educational Technology Research and Development 67(6), pp. 1547-1571. doi:10.1007/s11423-019-09693-0

Rivard, R. (2013). Measuring the MOOC dropout rate. Inside Higher Ed, 8, 2013.

Santos, O. C., Boticario, J. G., \& Pérez-Marín, D. (2014). Extending web-based educational systems with personalised support through User Centred Designed recommendations along the e-learning life cycle. Science of Computer Programming, 88, 92-109.

Saul, C., \& Wuttke, H. D. (2014, July). Turning Learners into Effective Better Learners: The Use of the askMe! System for Learning Analytics. In UMAP Workshops.

Schwendimann, B. A., Rodríguez-Triana, M. J., Vozniuk, A., Prieto, L. P., Boroujeni, M. S., Holzer, A., Gillet, D., \& Dillenbourg, P. (2016). Understanding learning at a glance: An overview of learning dashboard studies. ACM International Conference Proceeding Series, 25-29April-2016, 532-533. doi:10.1145/2883851.2883930

Simões, J., Redondo, R. D., \& Vilas, A. F. (2013). A social gamification framework for a K-6 learning platform. Computers in Human Behavior, 29(2), 345-353. doi:10.1016/j.chb.2012.06.007

Sitra, O., Katsigiannakis, V., Karagiannidis, C., \& Mavropoulou, S. (2017). The effect of badges on the engagement of students with special educational needs: A case study. Education and Information Technologies, 22(6), 3037-3046.

Upadhyaya, D., \& Garg, A. (2019, September). Leveraging on Gamification and Learning Analytics for Improved Student Learning. In 2019 International Conference on Computing, Power and Communication Technologies (GUCON) (pp. 132-138). IEEE.

Uz Bilgin, C., \& Gül, A. (2020). Investigating the Effectiveness of Gamification on Group Cohesion, Attitude, and Academic Achievement in Collaborative Learning Environments. TechTrends, 64(1), 124-136.

Verbert, K., Duval, E., Klerkx, J., Govaerts, S., \& Santos, J. L. (2013). Learning analytics dashboard applications. American Behavioral Scientist, 57(10), 1500-1509.

Zicherman, G. \& Cunningham, C. (2011). Gamification by Design: Implementing Game Mechanics in Web and Mobile Apps (1st ed.). Sebastopol, California: O'Reilly Media.

Zilvinskis, J., \& Willis III, J. E. (2019). Learning Analytics in Higher Education: A Reflection. InSight: A Journal of Scholarly Teaching, $14,43-54$. 